\title{
Triosephosphate isomerase of Mucor circinelloides is recognized as a main secreted antigen by sera from infected immunosuppressed mice
}

Arbizu-Delgado $A^{1}$, Guruceaga $X^{1}$, Antoran $A^{1}$, Martin-Souto $L^{1}$, Javier Capilla ${ }^{2}$, Adela Martin-Vicente ${ }^{2}$, Rementeria $A^{1}$, Hernando $\mathrm{FL}^{1}$, Ramirez-Garcia $\mathrm{A}^{\mathbf{1}}$.

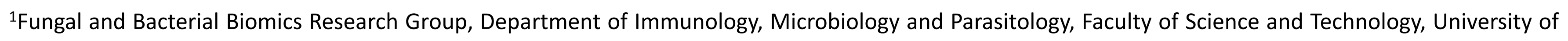
the Basque Country (UPV/EHU), Leioa, Spain.

${ }^{2}$ Mycology Unit, Medical School and IISPV, Universitat Rovira i Virgili, Reus, Spain.

\section{INTRODUCTION}

Mucormycosis, infections caused by fungi of the order Mucorales, are a group of emerging infectious diseases characterized by rapid progression and high aggressiveness. The genera Mucor is one of the most common etiological agents, being Mucor circinelloides the most frequently isolated species. Moreover, their virulence mechanisms are still unknown and there is no effective diagnostic method for this disease apart from classical methods.

\section{OBJECTIVE}

The aim of this study was to identify the secreted antigens of $M$. circinelloides recognized specifically by immunosuppressed infected mice sera.

\section{Protein obtention}

\section{RESULTS \& METHODS}

Mucor circinelloides was grown into potato dextrose broth at 370 C with $120 \mathrm{rpm}$ agitation for 24 hours. After that, the fungal material was separated from the medium by filtration and incubated at $37{ }^{\circ} \mathrm{C}$ with $120 \mathrm{rpm}$ agitation in PBS 2\% glucose for 20 hours.

Then, the supernatant was filtered, sterilized and dialyzed, and finally, proteins were precipitated by TCA/acetone method and resuspended in buffer for twodimensional electrophoresis (2-DE).

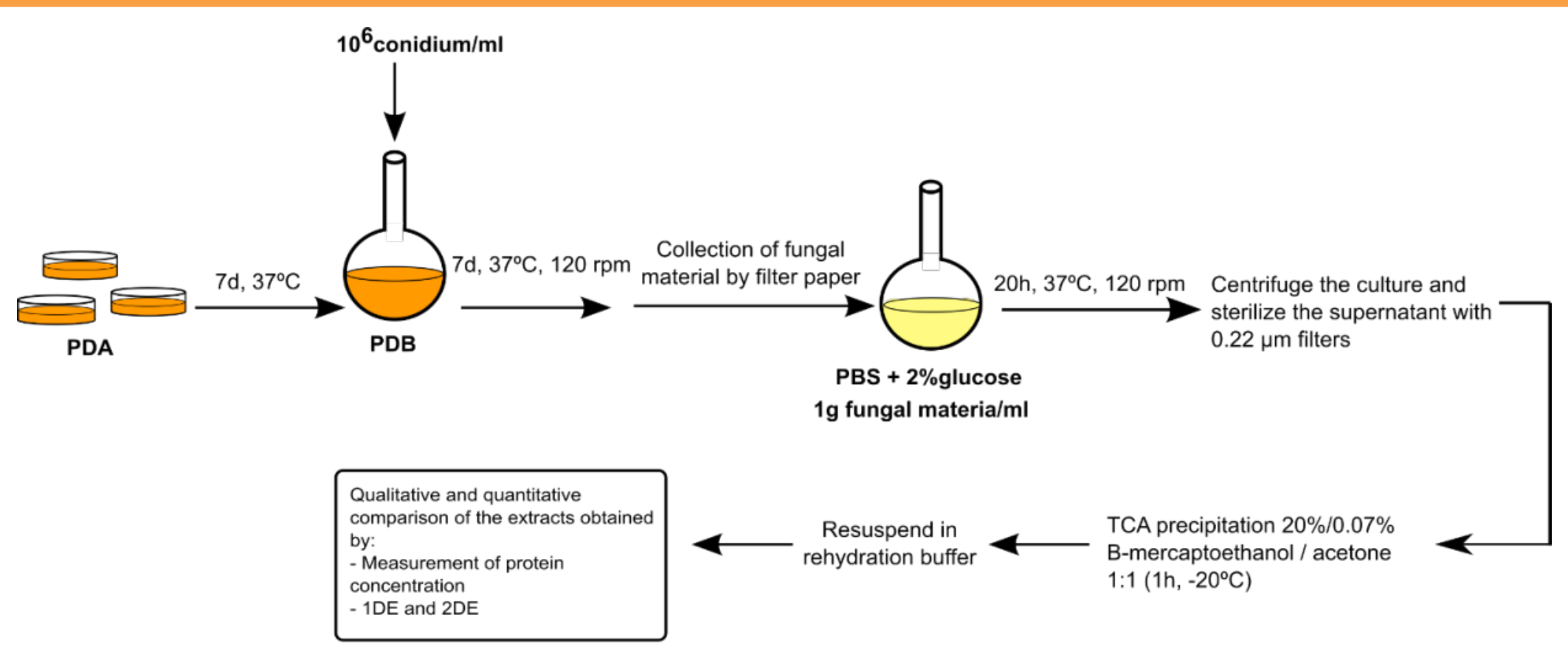

Fig. 1. Diagram of the workflow used for the obtention of the secretome proteins from $M$ - circinelloides.

\section{Protein separation and identification}

Protein separation was carried out by 2-DE and antigen detection was performed by Western Blot against a pool of sera obtained from 5 mice infected intravenously with $1 \times 10^{5}$ conidia of $M$. circinelloides NRRL 3631 and 5 control sera from non-infected mice- All of the mice were immunosuppressed by giving them $100 \mathrm{mg} / \mathrm{kg}$ cyclophosphamide intraperitoneally at -4 days and, then, every three days until the day 20 in which the mice were sacrificed and the sera was obtained.

Eight immunoreactive proteins were specifically detected by sera from infected immunosuppressed mice. Four of them were detected at isoelectric point ( $\mathrm{pl}$ ) of 5,4-5,7 and a molecular weight (Mr) of $50 \mathrm{kDa}$, which were identified as enolase by LC-MS/MS. The other four spots were the most immunoreactive and were identified as triosephosphate isomerase at 4,8 $-5,4 \mathrm{pl}$ and $\mathrm{Mr} 25 \mathrm{kDa}$.

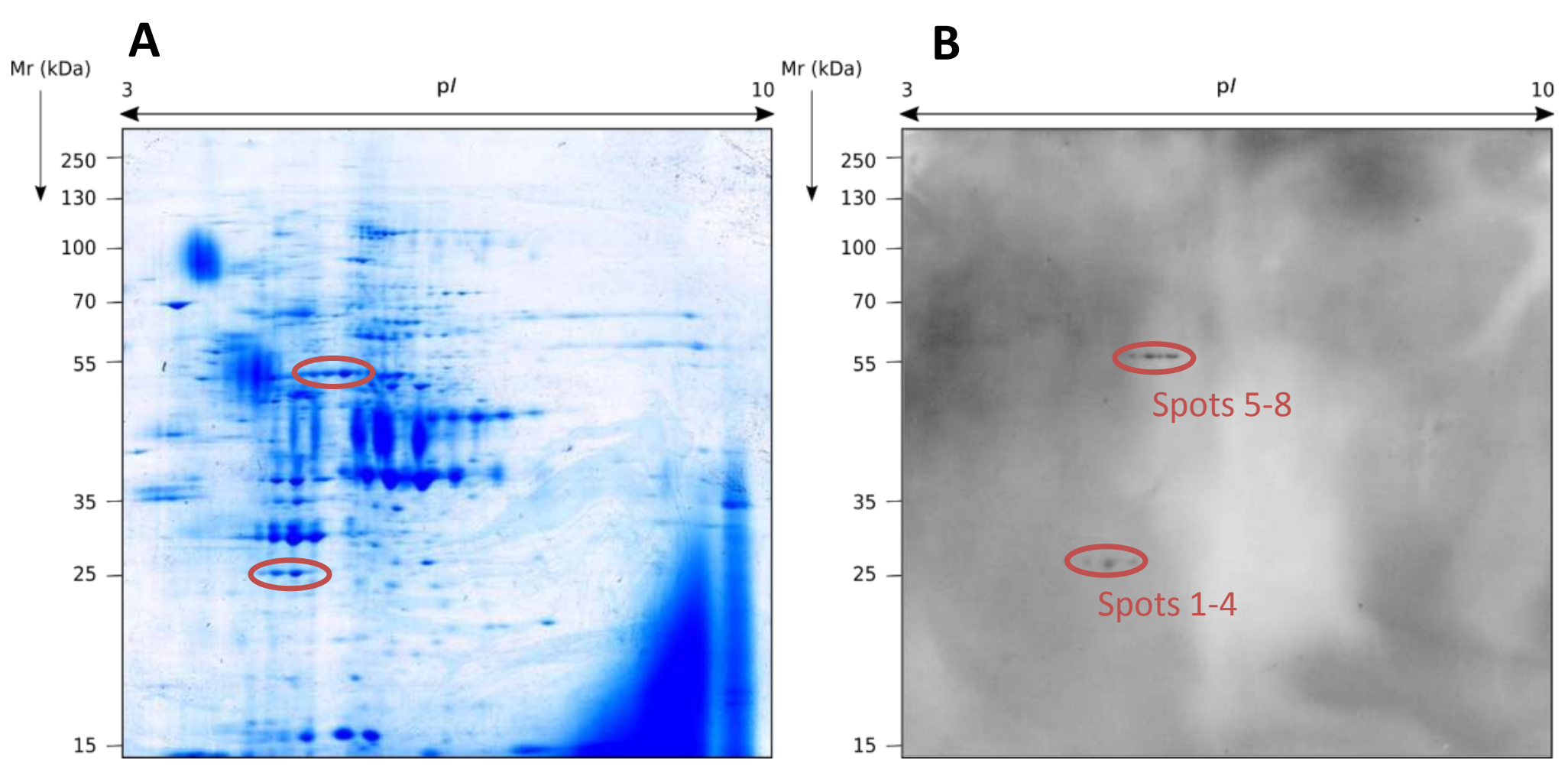

Table 1. Identified antigens of $M$. circinelloides in secretome.

\begin{tabular}{cc}
\hline Spot & Identified protein \\
\hline $\mathbf{1 , 2 , 3 , 4}$ & $\begin{array}{c}\text { Triosephosphate } \\
\text { isomerase }\end{array}$ \\
$5,6,7,8$ & enolase
\end{tabular}

Fig. 2. Two-dimensional proteome (A) and immunome (B) analysis of the secreted proteins.

\section{CONCLUSIONS}

Acknowledgements
$\checkmark$ This work has been supported by grants (GIU15/36 and PPG17/41) from
the UPV/EHU.
$\checkmark$ LM-S XG and AA were supported by predoctoral fellowships from the
Basque Government.

- Triosephosphate isomerase was identified, together with enolase, as a major secreted antigen of $M$. circinelloides.

- The study in depth of the immunoreactivity of this antigen should be accomplished to analyze its potential as target for diagnosis. 